\title{
Activation or anergy: NKT cells are stunned by $\alpha$-galactosylceramide
}

\author{
Barbara A. Sullivan and Mitchell Kronenberg
}

La Jolla Institute for Allergy and Immunology, San Diego, California, USA.

\begin{abstract}
Invariant natural killer $\mathrm{T}$ ( $\mathrm{iNKT}$ ) cells are $\mathrm{T}$ lymphocytes that behave similarly to cells of the innate immune system. The glycolipid $\alpha$-galactosylceramide ( $\alpha$-GalCer) is a potent and specific activator of mouse and human $i$ NKT cells and has been used in cancer clinical trials to drive NKT cell-mediated immune responses. However, little is known about the dynamics of the $i$ NKT cell response to $\alpha-G a l C e r$ in vivo. In this issue of the JCI, Parekh and colleagues demonstrate that administration of $\alpha$-GalCer causes $i$ NKT cells to become unresponsive, for at least 1 month, in mice (see the related article beginning on page 2572). This leads us to ask, should sequential administration of $\alpha$-GalCer still be used to activate $i$ NKT cells given the anergic state it has been shown here to induce? This intriguing article raises the issue of the avoidance of anergy induction in the design of treatment regimens that use $\alpha-$ GalCer as a specific activator of $i$ NKT cells.
\end{abstract}

Natural killer T (NKT) cells are specialized $\mathrm{T}$ cells of the immune system that express markers of the NK cell lineage, such as NK1.1. They recognize glycolipid antigens presented by the MHC class I-related protein CD1d (1). In mice, these cells are sometimes referred to as invariant NKT ( $i \mathrm{NKT}$ ) cells, because they express an invariant TCR consisting of a single $V \alpha$-to-J $\alpha$ rearrangement ( $V \alpha 14-J \alpha 18)$, paired with a restricted set of $V \beta$ chains

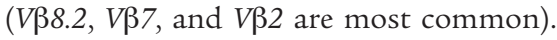
Human $i$ NKT cell TCRs express orthologous $\mathrm{V}$ segments, an invariant V $\alpha 24-J \alpha 18$ paired with $V \beta 11$. Human and mouse $i$ NKT cells react to the same glycolipid antigens, including $\alpha$-galactosylceramide ( $\alpha$-GalCer), which is presented by CD1d. Among T lymphocytes, $i$ NKT cells are unique in terms of the conservation of their specificity and activated phenotype; this suggests that studies elucidating key components of mouse $i$ NKT cell biology will likely also prove important for human $i$ NKT cells. However, humans have fewer CD1d-restricted $i$ NKT cells than mice.

\section{$\alpha$-GalCer activates and anergizes iNKT cells}

The glycolipid $\alpha$-GalCer (also called KRN7000) was originally identified in

Nonstandard abbreviations used: $\alpha$-GalCer, $\alpha$-galactosylceramide; $i$ NKT, invariant natural killer T (cell); NKT, natural killer T (cell).

Conflict of interest: The authors have declared that no conflict of interest exists.

Citation for this article: J. Clin. Invest. 115:2328-2329 (2005). doi:10.1172/JCI26297. a screen for antitumor activity of compounds derived from marine sponges (2). In mice, $\alpha$-GalCer activates $i \mathrm{NKT}$ cells within hours of injection, causing these cells to produce copious amounts of both regulatory and proinflammatory cytokines. Proinflammatory cytokines lead to the downstream transactivation of NK, T, and B cells as well as DCs. The NK cell activation that is dependent on activated $i$ NKT cells is essential for $\alpha$-GalCermediated tumor clearance in mice. Coadministration of a model protein antigen with $\alpha$-GalCer leads to the enhanced induction of specific T cell memory $(3,4)$. $\alpha$-GalCer is highly potent because of its strong binding to the $i$ NKT cell TCR and its long half-life (5). Additionally, $\alpha$-GalCer targets only $i$ NKT cells, as there is little bystander activation and little transactivation in mice lacking CD1d. Numerous investigators have used synthetic $\alpha$-GalCer, or its variants, in mouse models to prevent tumor metastases, to reduce autoimmunity in experimental autoimmune encephalomyelitis (EAE) and diabetes models, and to enhance the responses to viral and parasitic infections (6). Furthermore, $\alpha$-GalCer has been used in 4 phase I cancer clinical trials to date, with the ultimate purpose of determining whether the antitumor effects obtained in mice also will be observed in humans (7-10). Despite the interest in using $\alpha$-GalCer in the clinic to activate $i \mathrm{NKT}$ cells, little is known about the effects of repeated $\alpha$-GalCer administration in vivo. In this issue of the JCI, Parekh et al. provide what we believe to be the first description of the detailed long-term effects of $\alpha$-GalCer administration on $i$ NKT cells in vivo, in mice (11).

Parekh et al. (11) have demonstrated that a single injection of $\alpha$-GalCer induces long-term anergy of $i$ NKT cells in mice. What exactly is anergy? Ronald Schwartz, a pioneer in this field of study, calls it "a tolerance mechanism in which the lymphocyte is intrinsically functionally inactivated following an antigen encounter, but remains alive for an extended period of time in a hyporesponsive state" (12). Simply put, conventional $\mathrm{T}$ cells can be "stunned" by strong TCR signals delivered in the absence of costimulation. The $i \mathrm{NKT}$ cell anergy described by Parekh et al. has several features in common with the anergy of conventional $\mathrm{T}$ cells, as it is long lasting, independent of persistent antigen, cell autonomous, and reversible with administration of IL-2 (11). The authors also show that, as for conventional $\mathrm{T}$ cells, the block in activation of anergized $i$ NKT cells is at the level of the TCR. Culture of anergized $i$ NKT cells with PMA plus ionomycin, which bypasses proximal steps in TCR signaling, allowed the $i \mathrm{NKT}$ cells to respond by producing cytokines.

Do $i$ NKT cells become anergic when activated without costimulation? Parekh et al. do not address this issue directly; however, they do show that B cells presenting $\alpha$-GalCer can induce anergy in $i$ NKT cells whereas DCs do not (11). They speculate that this is due to the numbers of costimulatory molecules present on the surface of each cell type, with B cells having low numbers and DCs having higher numbers. Unlike conventional T cells, $i$ NKT cells do not require costimulation for rapid cytokine release (13). Mouse $i$ NKT cells may be activated initially in response to antigen and expand in number without costimulation, but may then adopt an anergic state. $i$ NKT cell anergy therefore may not be mechanistically identical to conventional $T$ cell anergy. 
In some cases, anergic cells also regulate the activation of other $\mathrm{T}$ cells. This does not seem to be the case for $i$ NKT cells, and they do not express Foxp3 (11), the transcription factor that acts as a master regulator for the generation and function of CD $25^{+}$Tregs. $i$ NKT cells normally produce both IFN- $\gamma$ and IL- 4 when activated by $\alpha$-GalCer, but Parekh et al. also show that while $i$ NKT cell anergy is characterized by a reduction in IL-4 production, there is a more severe drop in IFN- $\gamma$ production (11). $i$ NKT cell anergy may therefore potentially skew Th2 cytokine production, a fact that might explain the beneficial effects of repeated $\alpha$-GalCer treatment in the prevention of spontaneous diabetes in NOD mice $(14,15)$.

\section{Are glycolipid antigens ready for the clinic?}

Could the induction of $i$ NKT cell anergy be useful in the clinic? In some animal models, iNKT cells have deleterious effects, as shown in airway hypersensitivity models of human asthma $(16,17)$. In these cases, B cells loaded with $\alpha$-GalCer could be used to anergize mouse $i \mathrm{NKT}$ cells, and, potentially, this concept could be extended to humans as well. However, even when presented by a B cell, $\alpha$-GalCer induces the expression of numerous cytokines before the $i \mathrm{NKT}$ cells become anergic, and this could lead to morbidity. It is therefore perhaps more likely that avoiding anergy will be the key issue in future therapies aimed at activating $i$ NKT cells. Along those lines, phase I clinical trials have examined the utility of immunization with either $\alpha$-GalCer alone (7) or $\alpha$-GalCer-loaded immature $(8,9)$ or mature DCs (10) for the treatment of cancer. Consistent with mouse studies, delivery of $\alpha$-GalCer on mature DCs has proven to currently be the best way to expand $i$ NKT cell numbers: the $i$ NKT cell population was shown to expand dramatically (more than 100-fold) after
3 immunizations with $\alpha$-GalCer-loaded mature DCs (10).

What are the prospects for using glycolipid agonists to activate $i$ NKT cells in vivo? $i$ NKT cells are an exceptional target for immunotherapy, because of their swift and directed activation of the adaptive immune system. However, it might be worthwhile to investigate $i$ NKT cell anergy further in the context of targeting $\alpha$-GalCer to different APCs. Furthermore, new glycolipid ligands for $i$ NKT cells have been recently identified, including synthetic and naturally occurring antigens. The naturally occurring antigens isoglobotrihexosylceramide (iGb3; an autologous mouse antigen [ref. 18]) and GSL-1', a glycosphingolipid antigen from Sphingomonas bacteria that is structurally related to $\alpha$-GalCer $(19,20)$, stimulate $i$ NKT cells less strongly than $\alpha$-GalCer and might be good candidates for immunotherapy. Repeated injections of weaker compounds may be more effective in the avoidance of anergy, and therefore it will be critical to determine whether iGb3 and/or GSL-1' induce anergy in $i \mathrm{NKT}$ cells. This is needed for the development of glycolipid-containing adjuvants and vaccines and for any immunotherapy designed to stimulate $i$ NKT cells.

Address correspondence to: Mitchell Kronenberg, La Jolla Institute for Allergy and Immunology, 10355 Science Center Drive, San Diego, California 92121, USA. Phone: (858) 678-4540; Fax: (858) 225-0730; E-mail:mitch@liai.org.

1. Kronenberg, M., and Rudensky, A. 2005. Regulation of immunity by self-reactive T cells. Nature. 435:598-604

2. Kobayashi, E., Motoki, K., Uchida, T., Fukushima, H., and Koezuka, Y. 1995. KRN7000, a novel immunomodulator, and its antitumor activities. Oncol. Res. 7:529-534.

3. Fujii, S., Shimizu, K., Smith, C., Bonifaz, L., and Steinman, R.M. 2003. Activation of natural killer $\mathrm{T}$ cells by alpha-galactosylceramide rapidly induces the full maturation of dendritic cells in vivo and thereby acts as an adjuvant for combined CD4 and
CD8 T cell immunity to a coadministered protein. J. Exp. Med. 198:267-279.

4. Gonzalez-Aseguinolaza, G., et al. 2002. Natural killer T cell ligand alpha-galactosylceramide enhances protective immunity induced by malaria vaccines. J. Exp. Med. 195:617-624.

5. Sidobre, S., et al. 2004. The T cell antigen receptor expressed by Valpha14i NKT cells has a unique mode of glycosphingolipid antigen recognition. Proc. Natl. Acad. Sci. U. S. A. 101:12254-12259.

6. Godfrey, D.I., and Kronenberg, M. 2004. Going both ways: immune regulation via CD1d-dependent NKT cells [review]. J. Clin. Invest. 114:1379-1388. doi:10.1172/JCI200423594.

7. Giaccone, G., et al. 2002. A phase I study of the natural killer T-cell ligand alpha-galactosylceramide (KRN7000) in patients with solid tumors. Clin. Cancer Res. 8:3702-3709.

8. Nieda, M., et al. 2004. Therapeutic activation of Valpha24+Vbeta11+ NKT cells in human subjects results in highly coordinated secondary activation of acquired and innate immunity. Blood. 103:383-389.

9. Ishikawa, A., et al. 2005. A phase I study of alphagalactosylceramide (KRN7000)-pulsed dendritic cells in patients with advanced and recurrent non-small cell lung cancer. Clin. Cancer Res. 11:1910-1917.

10. Chang, D.H., et al. 2005. Sustained expansion of NKT cells and antigen-specific T cells after injection of alpha-galactosyl-ceramide loaded mature dendritic cells in cancer patients. J. Exp. Med. 201:1503-1517.

11. Parekh, V.V., et al. 2005. Glycolipid antigen induces long-term natural killer $\mathrm{T}$ cell anergy in mice. J. Clin. Invest. 115:2572-2583. doi:10.1172/JCI24762.

12. Schwartz, R.H. 2003. T cell anergy. Annu. Rev. Immunol. 21:305-334.

13. Matsuda, J.L., et al. 2003. Mouse V alpha 14i natural killer $T$ cells are resistant to cytokine polarization in vivo. Proc. Natl. Acad. Sci. U. S. A. 100:8395-8400.

14. Sharif, S., et al. 2001. Activation of natural killer $T$ cells by alpha-galactosylceramide treatment prevents the onset and recurrence of autoimmune type 1 diabetes. Nat. Med. 7:1057-1062.

15. Hong, S., et al. 2001. The natural killer T-cell ligand alpha-galactosylceramide prevents autoimmune diabetes in non-obese diabetic mice. Nat. Med. 7:1052-1056.

16. Lisbonne, M., et al. 2003. Cutting edge: invariant $\mathrm{V}$ alpha 14 NKT cells are required for allergeninduced airway inflammation and hyperreactivity in an experimental asthma model. J. Immunol. 171:1637-1641.

17. Akbari, O., et al. 2003. Essential role of NKT cells producing IL-4 and IL-13 in the development of allergeninduced airway hyperreactivity. Nat. Med. 9:582-588.

18. Zhou, D., et al. 2004. Lysosomal glycosphingolipid recognition by NKT cells. Science. 306:1786-1789.

19. Kinjo, Y., et al. 2005. Recognition of bacterial glycosphingolipids by natural killer T cells. Nature. 434:520-525.

20. Mattner, J., et al. 2005. Exogenous and endogenous glycolipid antigens activate NKT cells during microbial infections. Nature. 434:525-529. 